\title{
KARAKTERISTIK PEMANFAATAN POHON OLEH JALAK BALI (LEUCOSAR ROTHSCHILDI) DI TAMAN NASIONAL BALI BARAT WILAYAH SPTN III, BULELENG, BALI
}

\author{
Nirmala Ayu Aryanti ${ }^{1 *}$, Reyza Hermawan Wicaksono ${ }^{1)}$ \\ ${ }^{1}$ Jurusan Kehutanan, Fakultas Pertanian Peternakan, Universitas Muhammadiyah Malang Jl. Raya Tlogomas No.246 \\ Malang
}

*) Alamat korespondensi: nirmalaaaryanti@gmail.com

\begin{abstract}
ABSTRAK
Jalak Bali (Leucopsar rothschildi) merupakan jenis burung endemik yang hanya dapat ditemukan di hutan bagian barat Pulau Bali. Penangkapan liar dan menurunnya habitat hutan menjadi faktor utama menurunnya populasi. Taman Nasonal Bali Barat merupakan benteng terakhir. Kebiasaan hidup untuk beraktivitas dan bersarang di pepohonan menjadikan pentingnya keberadaan tegakan pohon untuk dipertahankan. Oleh karena itu, penelitian ini dilakukan dengan tujuan untuk mengetahui karakteristik pemanfaatkan pohon oleh burung Jalak Bali di habitat aslinya di SPTN III Taman Nasional Bali Barat. Metode yang digunakan adalah concentration count untuk mengetahui karakteristik pemanfaatan vegetasi oleh Jalak Bali berupa jenis pohon dan bagian ruang tajuk. Perilaku Jalak Bali di habitat aslinya diamati menggunakan metode Ad Libitum. Analisis data dilakukan dengan cara menghitung persentase pada tiap bagian penggunaan tajuk dan bentuk perilaku oleh Jalak Bali. Penggunaan tajuk pohon oleh Jalak Bali di SPTN III Labuhan Lalang TNBB untuk di Tanjung Gelap lebih sering pada bagian tajuk atas (TA), di Labuhan Lalang lebih sering pada bagian tajuk tengah (TT) dan tajuk tengah tepi (TTt). Secara keseluruhan aktivitas yang sering dilakukan Jalak Bali di tajuk pohon SPTN III Labuhan Lalang adalah sosial.
\end{abstract}

Kata kunci: Jalak Bali, pemanfaatan pohon, perilaku

\section{CHARACTERISTICS OF TREE USAGE BY JALAK BALI (Leucosar rothschildi) AT THE NATIONAL PARK OF WEST BALI SPTN III REGION, BULELENG, BALI}

\author{
Nirmala Ayu Aryanti ${ }^{1)^{*}}$, Reyza Hermawan Wicaksono ${ }^{1)}$
}

${ }^{1}$ Forestry Department, Faculty of Agriculture and Animal Husbandry, University of Muhammadiyah Malang, Jl. Raya Tlogomas No.246 Malang

*) Email: nirmalaaaryanti@gmail.com

\begin{abstract}
Leucopsar rothschildi (Jalak Bali) is an endemic bird species that only be found in the forests of the western of Bali Island. Wild catching and declining forest are the main factors of the declining population. The National Park of West Bali is the last bastion. The habit of living for activity and nesting in the trees make the importance of tree stand to be preserved. Therefore, this study was conducted to analyze the utilization's characteristics of trees by the birds in their original habitat in SPTN III West Bali National Park. The method used was concentration count to observe the characteristics utilization of trees and canopy. Behavior in their natural habitat was observed using Ad Libitum method. Data analysis was conducted by calculating percentage in each part of the usage of canopy and behavior type. The use of the canopy of trees in SPTN III of Labuhan Lalang TNBB by the birds for Tanjung Gelap was more frequent in the upper canopy (TA) section, in Labuhan Lalang more often in the middle canopy (TT) and the middle side canopy (TTt). Frequently activity in the canopy of SPTN III Labuhan Lalang by the birds was social activity.
\end{abstract}

Keywords: Jalak Bali, tree usage, behavior 


\section{PENDAHULUAN}

Indonesia memiliki 1615 spesies burung dengan 419 termasuk spesies endemik dan menjadi peringkat ke-4 di dunia setelah Brazil, Columbia dan Peru. Jalak Bali (Leucopsar rothschildi) merupakan salah satu jenis burung endemik yang hanya dapat ditemukan di hutan bagian barat Pulau Bali. Satwa ini merupakan jenis burung kicau dan penampilan yang elok sehingga banyak diminati masyarakat sebagai satwa peliharaan. Tingginya penangkapan liar dan menurunnya habitat hutan menyebabkan penurunan populasi burung Jalak Bali. Menurut IUCN Red List masuk dalam kategori Critically Endangered, dalam CITES masuk Appendix I. Peraturan diperkuat dengan Peraturan Pemerintah Nomor 7 Tahun 1999 menyatakan sebagai satwa langka yang nyaris punah dan tidak boleh diperdagangkan kecuali hasil penangkaran dari generasi ketiga atau indukan.

Habitat merupakan kawasan yang terdiri atas komponen biotik maupun abiotik yang dipergunakan sebagai tempat hidup dan berkembang biak bagi satwa liar. Tiap jenis satwa liar membutuhkan habitat tertentu yang dapat menunjang kehidupannya, sehingga antara satu jenis satwa dengan jenis lainnya belum tentu sama kondisi habitatnya. Taman Nasonal Bali Barat merupakan benteng terakhir habitat asli burung Jalak Bali, kebiasaan hidup untuk beraktivitas dan bersarang di pepohonan menjadikan pentingnya keberadaan tegakan pohon untuk dipertahankan. Penyediaan kondisi habitat yang sesuai dengan kebutuhan karakter hidup Jalak Bali perlu dilakukan agar keberadaan Jalak Bali tetap terjaga.

Oleh karena itu berdasarkan latar belakang tersebut perlu dilakukan penelitian dengan tujuan mengetahui karakteristik pemanfaatkan pohon dan perilaku burung Jalak Bali di habitat aslinya di SPTN III Taman Nasional Bali Barat. Penelitian ini nantinya dapat dijadikan dasar pengelola dalam upaya pengelolaan habitat sehingga mampu menunjang keberadaan burung Jalak Bali di habitat aslinya di barat Pulau Bali

\section{METODE PENELITIAN}

Penelitian dilaksanakan di SPTN III Taman Nasioanal Bali Barat bertempat di Labuhan Lalang dan Tanjung Gelap, dan dilaksanakan pada bulan Desember 2016 hingga Februari 2017. Metode yang digunakan untuk mengetahui karakteristik pemanfaatan pohon dengan concentration count. Pengamatan dilakukan pada lokasi yang sering dijumpai burung Jalak Bali berdasarkan informasi petugas di SPTN III Labuhan Lalang. Tiap perjumpaan individu Jalak Bali dilakukan pencatatan jenis pohon dan posisi individu tersebut secara vertikal berdasarkan pembagian ketinggian menurut Richard dan van Balen meliputi A $(>30$ m), B (20-30 m), C (5-19,9 m), D (1-4,9 m) dan E $(<1 \mathrm{~m})$. Serta mencatat penggunaan ruang tajuk berdasarkan pembagian ruang di antaranya tajuk atas (TA), tajuk tengah (TT), tajuk tengah bagian tepi (TTt), tajuk bawah bagian tepi (TBt) dan tajuk bawah (TB), untuk memudahkan pembagian ruang digunakan model arsitektur pohon [1].
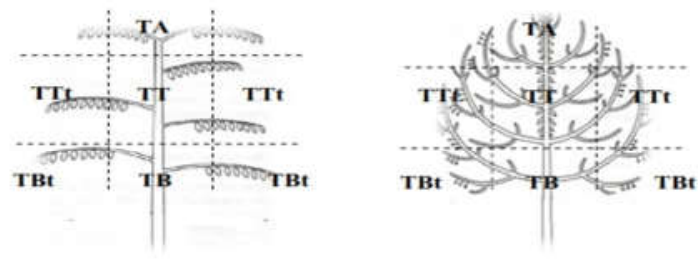

Keterangan:
Ruang tajuk: Tajuk atas (TA). Tajuk tengah (TT). Tajuk tengah bagian tepi (TTt), Tajuk bawah
bagian tepi (TBt). Tajuk bawah (TB)

Gambar 1. Pembagian ruang tajuk berdasarkan model arsitektur pohon [2]

Perilaku Jalak Bali dalam menggunakan pohon menggunakan metode Ad Libitum Sampling yaitu dengan mencatat seluruh jenis perilaku (makan, diam, siaga, membersihkan diri dan sosial) tiap perjumpaaan tanpa ada batasannya. Perilaku tersebut akan digunakan sebagai kategori perilaku yang akan diamati pada saat penelitian. Intensitas kehadiran penggunaan pohon pada bagian tajuk pohon dan bentuk perilaku Jalak Bali dihitung persentasenya kemudian dideskripsikan. 


\section{HASIL DAN PEMBAHASAN}

Dalam penggunaan jenis pohon berdasarkan hasil data di lapang yang ada di SPTN III Labuhan Lalang yang banyak digunakan Jalak Bali yaitu jenis pohon Intaran (Azadiractha indica) dengan jumlah 28 dan pohon Pilang (Acacia leucopliaa Willd) dengan jumlah 24 kali perjumpaan.

Tabel 3. Jenis Vegetasi yang digunakan oleh Jalak Bali

\begin{tabular}{|c|c|}
\hline \multicolumn{2}{|c|}{ Tanjung Gelap } \\
\hline Jenis Pohon & Jumlah \\
\hline Rhizophora apiculata Lamk & 2 \\
\hline Zizyphus mauritiana Lamk & 2 \\
\hline Ficus glabella Roxb & 6 \\
\hline Acacia leucopliaa Willd & 24 \\
\hline Coneratia alba & 1 \\
\hline Albizzia lebbeckoides Merr & 1 \\
\hline Grewia koordersiana & 16 \\
\hline Schoutenia ovata & 4 \\
\hline JUMLAH & 56 \\
\hline \multicolumn{2}{|c|}{ Labuhan Lalang } \\
\hline $\begin{array}{l}\text { Jenis Pohon } \\
\end{array}$ & Jumlah \\
\hline Acacia aurikuliformis Willd & 7 \\
\hline \multirow[t]{2}{*}{ Tamarindus indica $\mathrm{L}}$. & 5 \\
\hline & 1 \\
\hline Azadiractha indica & 28 \\
\hline Mangifera indica L. & 5 \\
\hline Acacia leucopliaa Wild & 5 \\
\hline Laneaa coromandelica Merr & 6 \\
\hline Manilkara kauki Dub & 11 \\
\hline JUMLAH & 68 \\
\hline
\end{tabular}

Pohon Pilang disukai oleh Jalak Bali dikarenkan pada musim penghujan pohon Pilang terdapat ulat yang merupakan salah satu makanan Jalak Bali di alam. Jalak Bali menyukai pohon Intaran dikarenkan pohon Intaran menghasilkan buah yang merupakan salah satu sumber makanan Jalak Bali. Di Pulau Bali, pohon Intaran menjadi tempat bertengger, buah sumber pakan bagi burung Jalak Bali [3].

Dalam penggunaan tajuk pohon terbanyak yang digunakan oleh Jalak Bali di SPTN III Labuhan Lalang dalam beraktivitas bila dirata-rata yaitu pada bagian tajuk atas (TA) sebesar 13,17\% dan tajuk tengah (TT) sebesar 13,02\%. Di Tanjung Gelap bagian tajuk pohon paling sering digunakan beraktivitas Jalak Bali pada tajuk tengah (TT) dan tajuk tengah bagian tepi (TTt). Sedangkan di Labuhan Lalang bagian tajuk yang sering digunakan adalah bagian tajuk atas (TA). Perbedaan tersebut dikarenakan kondisi tegakan pohon di Labuhan Lalang kurang rapat sehingga burung mencari tempat berlindung. Bagian tengah tajuk dan samping merupakan tempat yang nyaman dan aman dari terik matahari dan bersembunyi, serta memudahkan berpindah satu pohon ke pohon yang lain. Pada Tanjung Gelap kondisi tegakan yang rapat sehingga memudahkan burung untuk hinggap dan memperoleh makanan. Pemilihan area pada puncak tajuk lebih tinggi karena kemudahan dalam hinggap dan mengambil makanan, serta lebih aman dari gangguan. Burung Jalak Bali di Tanjung Gelap lebih sensitif terhadap kehadiran manusia. Pemilihan tajuk bagian atas karena kemudahannya mendatangi tempat tersebut dan persaingan dengan jenis lain [4].

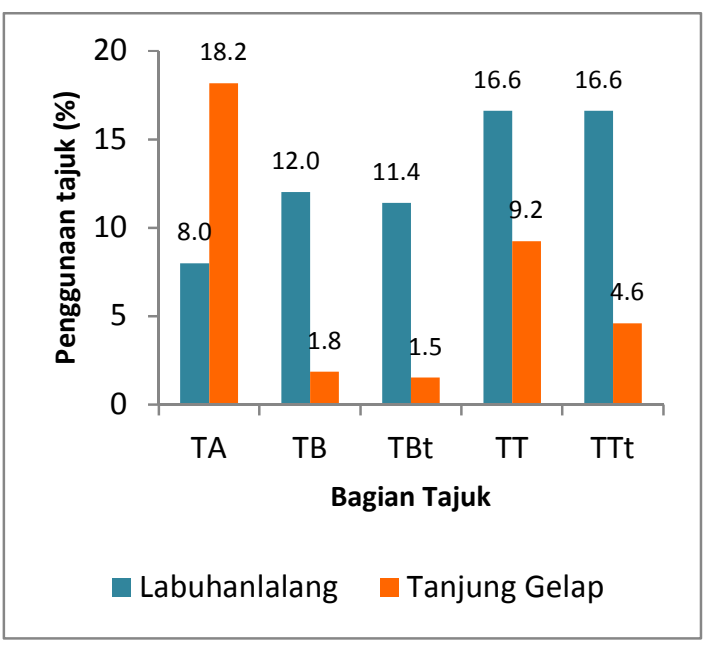

Gambar 3. Persentase penggunaa tajuk pohon oleh Jalak Bali (Leucopsar rothschildi) di SPTN III Labuhan Lalang

Pada tajuk bagian samping juga banyak dipilih oleh burung karena kemudahan dalam berpindah dari satu pohon ke pohon lainnya. Kedua bagian area ini banyak dipilih oleh burungburung yang memakan buah. Sedangkan pada bagian tengah tajuk lebih terlindung sehingga banyak dipilih oleh burung-burung kecil yang lincah dalam berpindah-pindah [5]. Stratifikasi penggunaan ruang secara horizontal pada berbagai tipe habitat di alam, menunjukkan adanya kaitan 
antara burung dengan lingkungan hidupnya, terutama dalam pola adaptasi dan strategi untuk mendapatkan sumber daya. Tiap jenis burung akan menempati habitat yang sesuai dengan kebutuhannya [6].

Aktivitas sosial adalah aktivitas antara lain berdekatan dan bombling (menegakkan jambul dan menggangguk-angguk sebagai bentuk mencari perhatian), perilaku tersebut paling sering dilakukan oleh Jalak Bali di SPTN III Labuhan Lalang. Pada habitat alami Jalak Bali termasuk jenis burung yang suka terbang berombongan, pada musim kawin yang berlangsung antara bulan September-Desember mereka terbang secara berpasangan sambil mencari berpasangan dan mencari makan [7]. Selain itu aktivitas bentuk sosial seperti bombling bertujuan untuk mencari perhatian atau berinteraksi antarburung dan dapat dilakukan oleh individu jantan maupun betina.

Aktivitas siaga menjadi aktivitas tertinggi berikutnya, bertujuan untuk melindungi betina saat menjaga sarang pada musim berbiak. Jalak Bali melakukan aktivitas siaga dengan cara posisi tegak dan mengamati lingkungan sekitar. Burung jantan pada umumnya memiliki sifat melindungi, lebih agresif, dan lebih berani terhadap gangguan dibandingkan dengan burung betina [8].

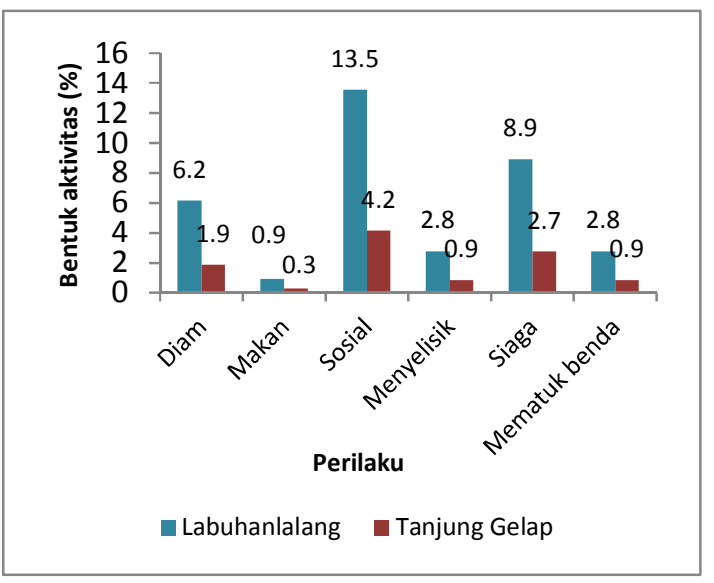

Gambar 4. Persentase bentuk aktivitas penggunaan tajuk pohon oleh jalak bali di Bali (Leucopsar rothschildi) di SPTN III Labuhan Lalang

Menyelisik kemudian menjadi aktivitas tinggi berikutnya, merupakan aktivitas memelihara bulu dengan menggigit atau menggerakkan paruh di antara sela-sela bulu. Kaki burung juga dimanfaatkan untuk menggaruk bagian kepala yang tidak dapat tersentuh oleh paruh.

\section{KESIMPULAN}

Penggunaan tajuk pohon oleh Jalak Bali di SPTN III Labuhan Lalang TNBB untuk di Tanjung Gelap lebih sering pada bagian tajuk atas (TA), di Labuhan Lalang lebih sering pada bagian tajuk tengah (TT) dan tajuk tengah tepi (TTt). Aktivitas yang sering dilakukan Jalak Bali di tajuk pohon SPTN III Labuhan Lalag adalah sosial baik di Labuhan Lalang dan Tanjung Gelap.

\section{DAFTAR PUSTAKA}

[1] Halle, F. \& R.A.A. Oldeman, 1975. An essay on the architechture and dynamics of growth of tropical trees. University Malaya. Kuala Lumpur. Malaysia

[2] Firoroh, I., 2009. Kajian profil vegetasi terhadap konsevasi air (aliran batang, curahan hujan dan infiltrasi) di Kebun Campur Sumber Tirta Senjoyo Semarang. (Tesis). Sekolah Pasca Sarjana IPB, Bogor

[3] Ginantra, I.K., A.A.G. Dalem, S.K. Sudirga \& I.G.N.B. Wirayudha, 2009. Jenis-jenis tumbuhan sebagai sumber pakan Jalak Bali (Leucopsar rothschildi) di Desa Ped, Nusa Penida, Klungkung Bali. Jurnal Bumi Lestari. 9(1): 97-102

[4] Mardiastuti, L.R. Salim \& Y.A. Mulyani, 1999. Perilaku makan rangkong Sulawesi pada dua jenis Ficus di Suaka Margasatwa Lambusango, Buton. Media Konservasi. 6(1): 7-10

[5] Surya, D.C., W. Novarini \& A. Arbain, 2013. Jenis-jenis burung yang memanfaatkan Eurya acuminata DC di kampus Universitas Andalas Limau Manis, Padang. Jurnal Biologi Universitas Andalas. 2(2): 90-95

[6] Wisnubudi, G. 2009. Penggunaan strata vegetasi oleh burung di kawasan wisata Taman Nasional Gunung Halimun - Salak. Vis Vitalis. 2(2): 41-49

[7] Kurniasih, L. 1997. Jalak Bali (Leucopsar rotschildii Stresemann 1912) spesies yang makin langka di habitat aslinya. Makalah Ilmiah Biosfer. 9: 3-7. 
[8] Takandjandji M, Kayat \& GND.Njurumana 2010. Perilaku burung bayan sumba (Eclectus roratus cornelia Bonaparte) di Penangkaran Hambala, SumbaTimur, Nusa Tenggara Timur. Jurnal Penelitian Hutan dan Konservasi Alam. 3(4): 357-369 